\title{
Perancangan Sistem Pelaporan Absensi Berbasis Web pada PT. Solar Control Specialist (SCS)
}

\author{
Pramitha Dwi Larasati ${ }^{1}$, Nur Fajri Sa'ba ${ }^{2}$ \\ 1,2 Prodi Sistem Informasi, School of Engineering and Technology, Tanri Abeng University \\ pramitha.dwi@tau.ac.id ${ }^{1}$, fajri.saba@student.tau.ac.id²
}

Diterima : 31 Agustus 2021

Disetujui : 28 September 2021

\begin{abstract}
Kemudahan akses internet saat ini dapat dimanfaatkan dengan baik dalam pengembangan sistem informasi pada perusahaan maju. Pengembangan tersebut salah satunya dapat dimanfaatkan untuk pelaporan absensi secara online. PT. SCS merupakan perusahaan yang mengembangkan sistem pelaporan absensi berbasis Web. Untuk menyelesaikan permasalah pelaporan absensi pegawai. Permasalahan yang dihadapi adalah pada saat pegawai (teknisi dan tenaga kerja lapangan) melakukan absensi, diwajibkan untuk melakukan finger print terlebih dahulu sebelum melakukan pekerjaan. Hal tersebut dirasa cukup berat, diakarenakan teknisi dan tenaga kerja lapangan diharuskan untuk menangani masalah pelanggan terlebih dahulu. Kadang kala jarak dari tempat pelanggan dan kantor cukup jauh membuat teknisi dan tenaga kerja lapangan kewalahan untuk melakukan absen tepat waktu. Pengembangan sistem ini dibuat menggunakan metode Waterfall serta SWOT Analysis untuk dapat mendefinisikan kebutuhan sistem. Pengumpulan data dilakukan dengan melakukan observasi dan wawancara. Adapun perancangan sistem ini dibuat dengan UML Diagram dilanjutkan dengan perancangan layout sistem. Hasil dari penelitian ini adalah perancangan sistem pelaporan absensi berbasis Web yang dapat membantu menyelesaikan permasalahan tersebut.
\end{abstract}

Keywords - Metode Waterfall, UML Diagram, SWOT Analysis, Web

\section{PENDAHULUAN}

Informasi menjadi salah satu sumber daya yang sangat penting bagi perkembangan sebuah perusahaan danmenjadi bagian dari manajemen dalam pengambilan keputusan serta penyusunan rencana jangka panjang. Dalam proses mendapatkan informasi tersebut, diperlukan adanya sebuah sistem yang membantu pengolahan data yang dimiliki perusahaan menjadi sebuah informasi yang berguna bagi manajemen. Maka dari itu dalam pemenuhan tersebut, maka dibuatlah sebuah sistem informasi.

Sistem informasi merupakan komponen yang terbagi atas manusia, teknologi informasi, dan cara kerja dalam melakukan pengolahan, penyimpanan, penganalisaan serta penyebaran informasi dalam mencapai tujuan yang diinginkan [2]. Pengembangan sistem informasi dapat dilakukan menjadi 2 bagian, yaitu sistem informasi manual dan sistem informasi berbasis komputer. Perkembangan sistem informasi berbasis komputer pada saat ini sudah menjadi sebuah kebutuhan yang sangat bermanfaat dalam membantu menyelesaikan permasalahan dalam perusahaan.

Permasalahan utama yang menjadi perhatian beberapa perusahaan yang ada di Jakarta, salah satunya adalah permasalahan absensi pegawai. Data absensi pegawai ini sangat krusial karena akan mempengaruhi data kehadiran, perizinan, perjalanan dinas serta mempengaruhi penerimaan upah pegawai. Dalam upaya 
menyelesaikan masalah absensi pegawai, maka diperlukan sebuah pengembangan teknologi.

Pengembangan sistem absensi sudah banyak dilakukan, salah satunya pengembangan sistem absensi berbasis Web pada CV. Cahaya Toner, pengelolaan absensi pegawai oleh bagian kepegawaian menjadi lebih. Sistem ini dibuat lebih user friendly berdasarkan keutuhan, dan manager bisa mengolah data pegawai serta melihat absensi pegawai. Pengembangan sistem ini dilakukan dengan memanfaatkan Web sehingga selaras dengan penggunaan akses internet yang sudah dapat dilakukan oleh semua pegawai perusahaan. Sehingga memudahkan pegawai mengakses sistem ini dari manapun [4].

Selain itu Pengembangan front end sistem informasi manajemen absensi pegawai Avatar Solutions dibuat dengan sederhana sesuai dengan kebutuhan yang didefinisikan user. Pengembangan sistem ini dibuat dengan menggunakan metode Waterfall dan perancangan menggunakan UML Diagram. Dengan adanya pengembangan front end yang sesuai kebutuhan ini dapat membantu dalam permasalahan absensi yang dilakukan oleh pegawai CV. Avatar Solutions [3].

PT. Solar Control Specialist (SCS) adalah perusahaan tekstil yang berpusat di Sunter, Kemayoran Jakarta Utara. PT. SCS mengalami permasalahan dalam pengelolaan data absensi dikarenaan beberapa hal, antara lain; pelaporan absensi dilakukan menggunakan finger print yang tersedia di kantor. Untuk pegawai (teknisi dan tenaga kerja lapangan) membuat pegawai tersebut harus datang ke kantor terlebih dahulu untuk absen (masuk-pulang) tapi pada posesnya pegawai tidak bisa lapor absensi dikantor karena diwajibkan langsung melakukan pemasangan dipagi hari ditempat yang telah diatur oleh staff depo cabang atau disebut Kortek (Koordinator Teknisi). Alhasil, penggunaan finger print menjadi tidak efektif dan membuat penggunaan pegawai tersebut melakukan absensi menggunakan kertas pebuatan laporan form dinas untuk teknisi. Pegawai lain seperti kurir dan tim claim juga memilik masalah yang sama yaitu tidak dapat melakukan lapor absen pagi dikantor karena tugas dinas pagi diluar dan juga harus membuat form dinas.

Hal-hal tersebut menyebabkan pengelolaan data absensi pegawai menjadi tumpang tindih dan cukup memakan waktu untuk merapihkan. Rekapitulasi laporan absensi dalam prosesnya perlu dilakukan penyocokan data dari laporan absen finger print dan laporan form dinas. Selain itu pengolahan data akhir menjadi laporan absensi pegawai pun masih dilakukan secara manual.

Berdasarkan dari penjabaran dari masalah yang dihadapi oleh PT. Solar Control Specialist, maka penulis membuat desain $W e b$-based sistem pelaporan absensi pegawa pada PT. Solar Control Specialist dengan menggunakan metode Waterfall dan UML Diagram untuk perancangan sistem.

\section{Metode Penelitian}

Penelitian ini dilakukan dengan mengadopsi tahap Requirement Definition serta System and Software Design yang merupakan bagian dari Metode Waterfall [5] sepeti yang ditunjukkan dalam gambar 1 .

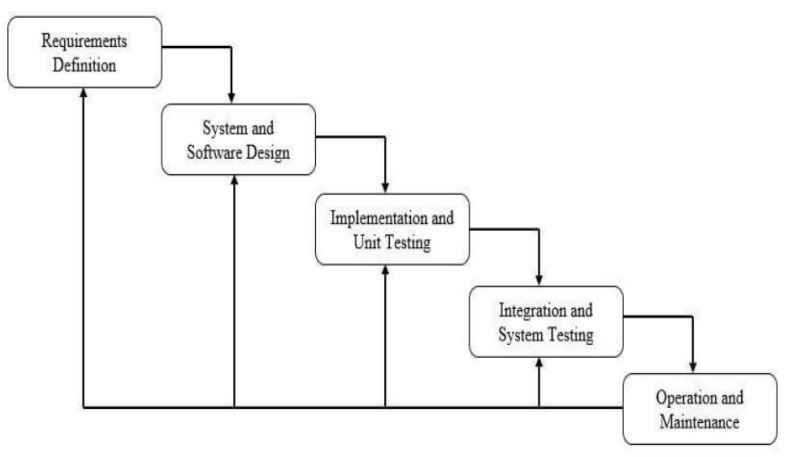

Gambar 1. Waterfall Method

Penggunaan kedua tahapan tersebut bertujuan untuk dapat memaksimalkan arah pengembangan agar sesuai dengan kebutuhan sistem yang telah didefinisikan berdasarkan kebutuhan dan permasalahan yang dihadapi oleh perusahaan. Dengan demikian, penelitian ini dilakukan dengan 4 (empat) tahapan. (1) Tahapan awal 
yang dilakukan adalah perencanaan. Perencanaan ini difokuskan kepada scheduling dan monitoring persiapan penelitian. (2) Peneliti melakukan observasi dan wawancara kepada user untuk mengumpulkan data yang dibutuhkan. (3) Setelah mendapatkan dan mengumpulkan data-data tersebut, peneliti menganalisis masalah-masalah yang dihadapi, ancaman yang ada, kekuatan yang dimiliki, kemungkinan yang dapat terjadi baik itu peluang ataupun ancaman yang akan dihadapi perusahaan dengan menggunakan SWOT Analysis [1]. Selanjutnya, peneliti juga mendefinisikan system needs berdasarkan kebutuhan perusahaan dan hasil dari SWOT Analysis. (4) Pada tahapan desain sistem, penelitian ni menggunakan $U M L$ Diagram seperti Usecase, Activity, Class dan Sequence Diagram untuk mengetahui keterlibatan users serta proses yang terjadi dalam sistem. Pada tahap ini juga akan dirancang layout tampilan sistem. Adapun metodologi penelitian untuk penelitian ini, ditunjukkan pada gambar 2 .

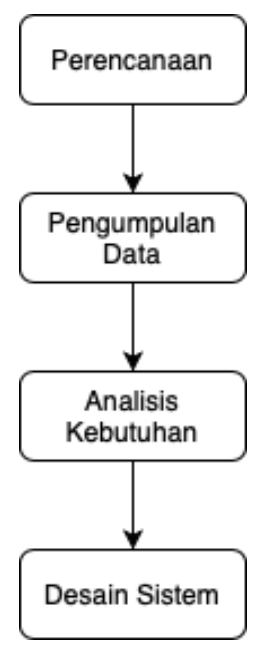

Gambar 2. Metodologi Penelitian

\section{HASIL DAN PEMBAHASAN}

\section{A. SWOT Analysis}

Analisis SWOT (Strength, Weakness, Opportunities and Threat) ini berfungsi menganalisis perencanaan dan strategis pada perusahaan yang digunakan untuk memonitor dan mengevaluasi seluruh direksi manajemen perusahaan dari sektor internal maupun sektor eksternal perusahaan dengan maksud tujuan bisnis yang ingin dicapai. Hasil analisis SWOT yang dilakukan ditunjukkan pada tabel 1 .

Tabel 1. SWOT Analysis

\begin{tabular}{|l|l|l|}
\hline & \multicolumn{1}{|c|}{ Strength } & \multicolumn{1}{c|}{ Weakness } \\
\hline $\begin{array}{l}\text { Oppor- } \\
\text { tunities }\end{array}$ & $\begin{array}{l}\text { Pelaporan absensi } \\
\text { dapat dilakukan } \\
\text { dengan cepat } \\
\text { dikarenakan akan } \\
\text { langsung terhubung } \\
\text { dengan sistem, dan } \\
\text { dapat diakses } \\
\text { menggunakan } \\
\text { smartphone serta data } \\
\text { yang tersimpan akan } \\
\text { tersusun dengan rapih } \\
\text { dan mudah diakses }\end{array}$ & $\begin{array}{l}\text { Pengembangan yang } \\
\text { dilakukan memerlukan } \\
\text { waktu dalam } \\
\text { pengintegrasi data } \\
\text { yang sudah ada. } \\
\text { Pengembangan yang } \\
\text { dilakukan selanjutnya } \\
\text { dapat menerapkan face } \\
\text { recognition. }\end{array}$ \\
\hline Treat & $\begin{array}{l}\text { Pengembangan } \\
\text { sistem harus } \\
\text { menggunakan } \\
\text { kemanan data yang } \\
\text { cukup secure terkait } \\
\text { data probadi } \\
\text { pegawai. }\end{array}$ & $\begin{array}{l}\text { Penerapan sistem ini, } \\
\text { membutuhkan } \\
\text { sosialisasi berkala agar } \\
\text { sistem dapat } \\
\text { dimanfaatkan secara } \\
\text { maksimal oleh seluruh } \\
\text { pegawai. }\end{array}$ \\
\hline
\end{tabular}

Berdasarkan dari hasil analisis SWOT yang telah dijabarkan, terlihat bahwa kebutuhan utama dari sistem pelaporan absensi yang dibuat adalah sistem berbasis web, dengan tingkat keamnan yang tinggi untuk menyimpan data-data pribadi karyawan terkait kehadiran sehingga dapat terhubung langsung dengan bagian finance.

\section{B. Desain Sistem}

Desain sistem dilakukan dengan mendefinisikan kebutuhan sistem, kebutuhan yang didefinisikan adalah kebutuhan fungsional, kebutuhan data, kebutuhan tenologi dan kebutuhan non-fungsional seperti yang dijabarkan pada tabel 2 .

Tabel 2. Kebutuhan Sistem

\begin{tabular}{|c|c|c|}
\hline No & Kebutuhan & Keterangan \\
\hline 1 & $\begin{array}{l}\text { Kebutuhan } \\
\text { Fungsional }\end{array}$ & $\begin{array}{ll}\text { - } & \text { Mengelola Absensi } \\
& \text { Pegawai } \\
\text { - } & \text { Mengelola Laporan Dinas } \\
\text { - } & \text { Mengelola Cuti dan Izin } \\
& \text { Pegawai } \\
\text { - } & \text { Rekapitulasi Kehadiran } \\
& \text { pegawai }\end{array}$ \\
\hline 2 & $\begin{array}{l}\text { Kebutuhan } \\
\text { Data }\end{array}$ & $\begin{array}{ll}\text { - } & \text { Data Pegawai } \\
\text { - } & \text { Data Kehadiran } \\
\text { - } & \text { Data Laporan Dinas }\end{array}$ \\
\hline 3 & $\begin{array}{l}\text { Kebutuhan } \\
\text { Teknologi }\end{array}$ & Internet Berbasis $W e b$ \\
\hline
\end{tabular}




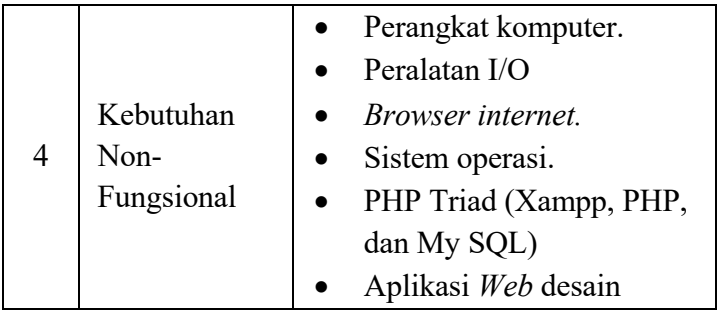

Setelah mendefinisikan kebutuhan sistem, peneliti akan merancang usecase diagram. Use case diagram digunakan untuk mengetahui aktor yang terlibat serta proses yang terjadi dalam sistem ini. Aktor yang terlibat untuk sistem ini adalah admin, pegawai, kepala bagian dan HRD. Use case diagram ditunjukkan pada gambar 3 .

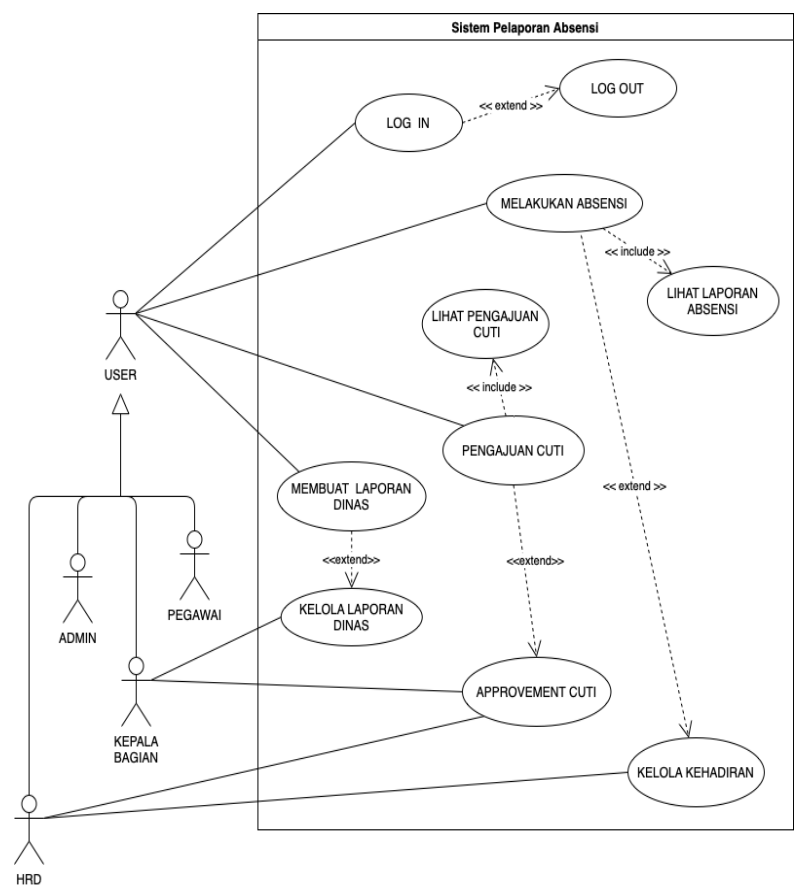

Gambar 3. Use case Diagram

Setelah merancangan use case diagram, maka diperlukan aktivitas yang terjadi antara aktor dengan proses yang telah didefinisikan. Untuk itu dilakukan perancangan activity diagram melakukan absensi yang ditunjukkan dalam gambar 4. Selain itu dibuat pula activity diagram untuk pengajuan cuti yang dilakukan dalam sistem yang ditunjukkan pada gambar 5 .

Class Diagram yang ditunjukkan dalam gambar 6, dirancang untuk mengetahui objek potensial yang akan dibuat pada saat perancangan database sistem. Adapun sistem ini memiliki 7 (tujuh) class yang akan digunakan.

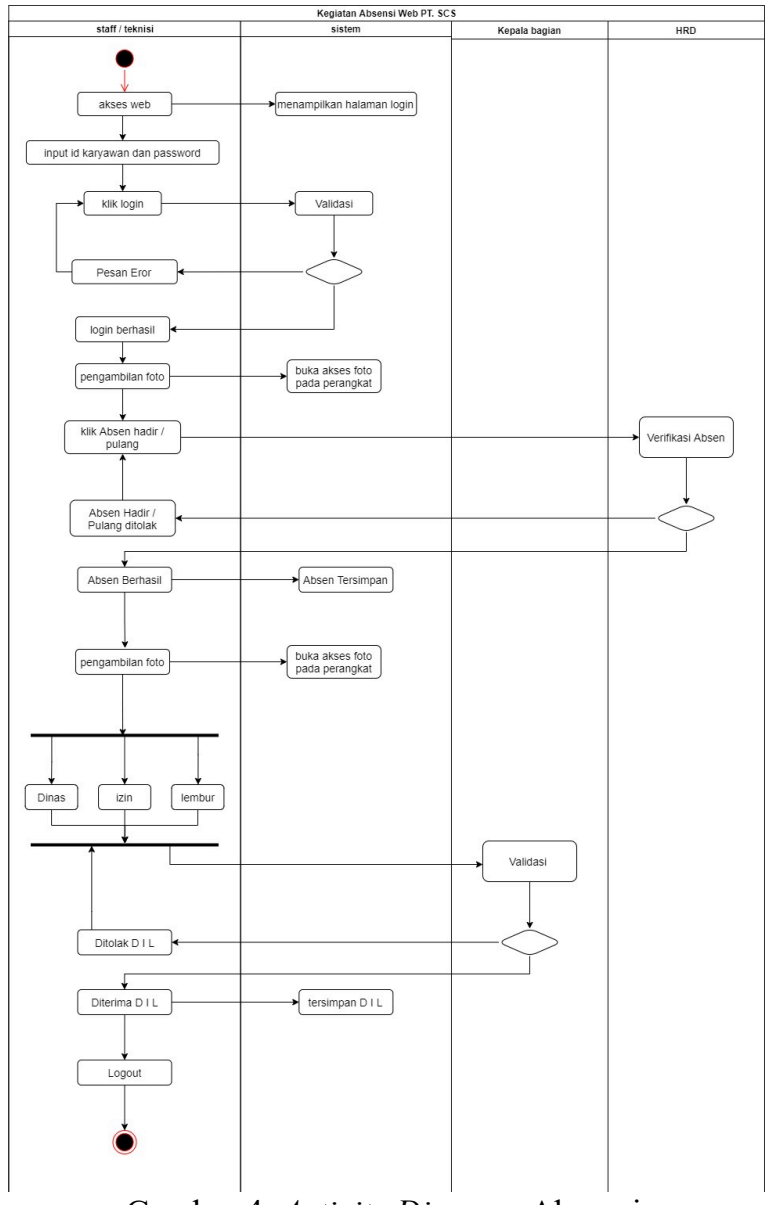

Gambar 4. Activity Diagram Absensi

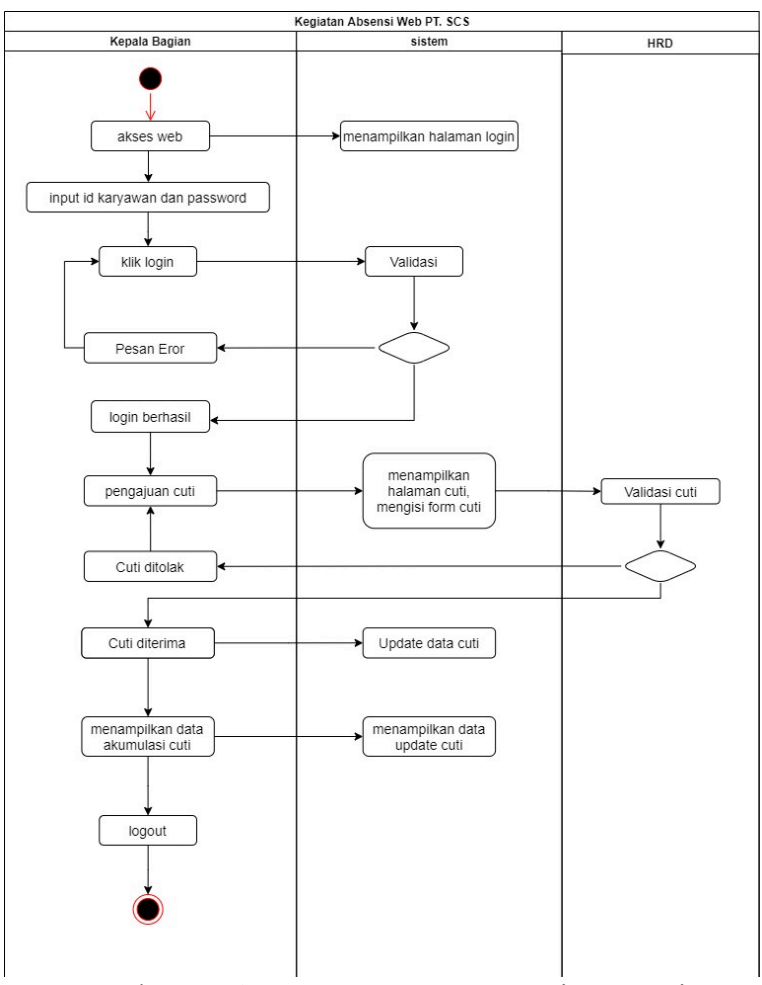

Gambar 5. Activity Diagram Pengajuan Cuti 


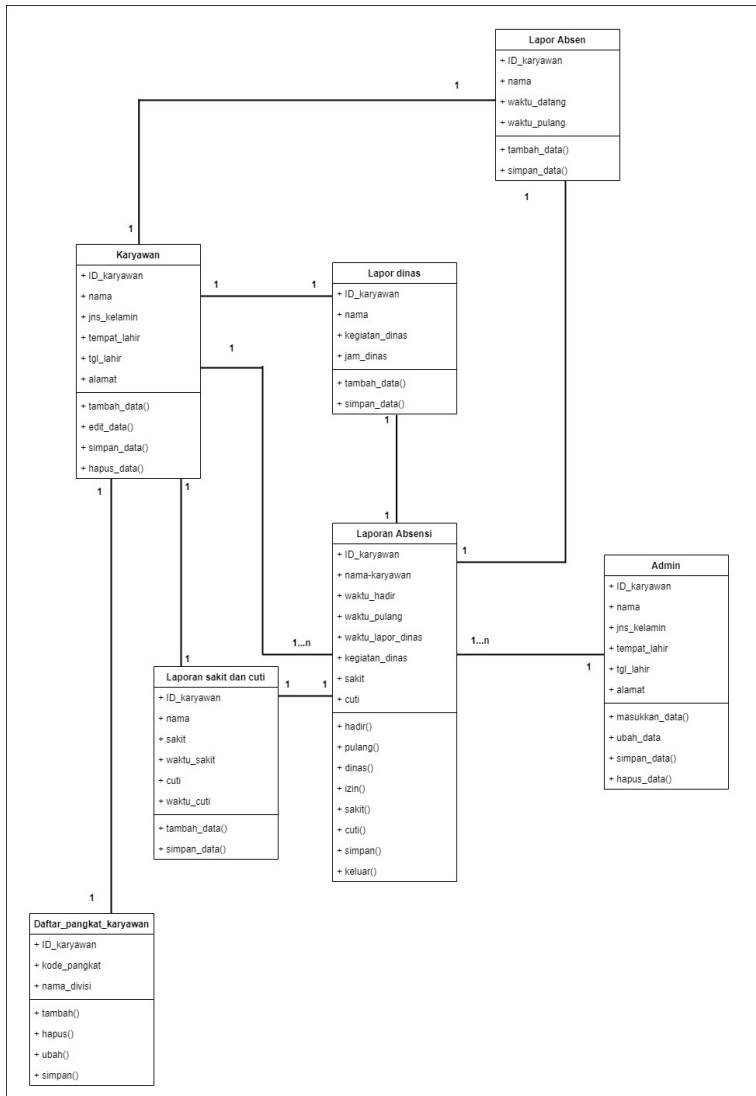

Gambar 6. Class Diagram

Setelah itu, dibuat sequence diagram yang bertujuan untuk mengetahui keterlibatan aktor, proses yang terjadi serta data yang dibutuhkan dalam proses-proses yang telah didefinisikan sebelumnya. Sequence diagram sistem ini ditunjukkan dalam gambar 7 dan gambar 8 .

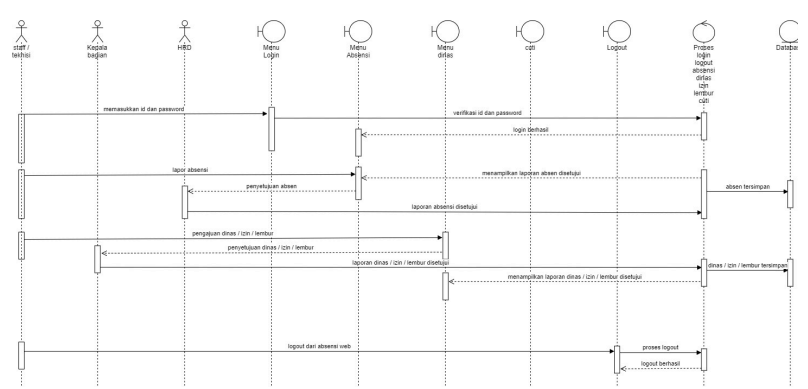

Gambar 7. Sequence diagram Absensi

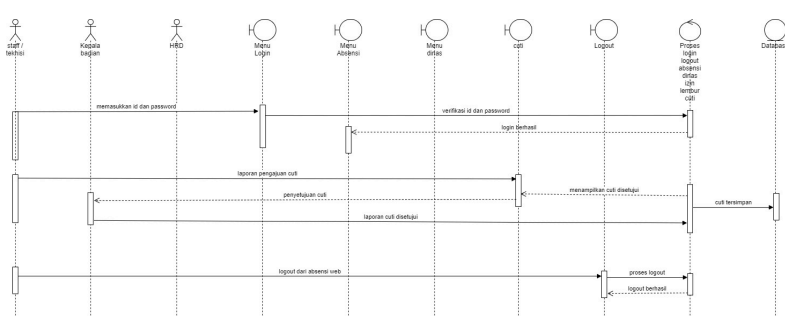

Gambar 8. Sequence diagram Pengajuan Cuti

\section{Layout System}

Setelah melakukan perancangan sistem menggunakan UML Diagram, selanjutnya adalah membuat layout tampilan dalam sistem yang dibuat. gambar 9 merupakan layout tampilan untuk halaman $\log$ in.

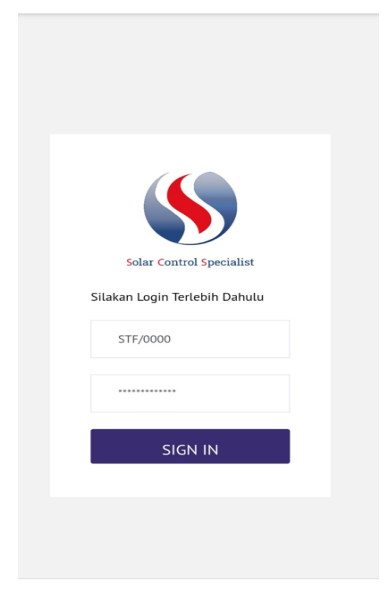

Gambar 9. Layout halaman Log in

Setelah melakukan $\log$ in, sistem akan menampilkan halaman utama. Layout halaman utama yang dibuat ditunjukkan dalam gambar 10.

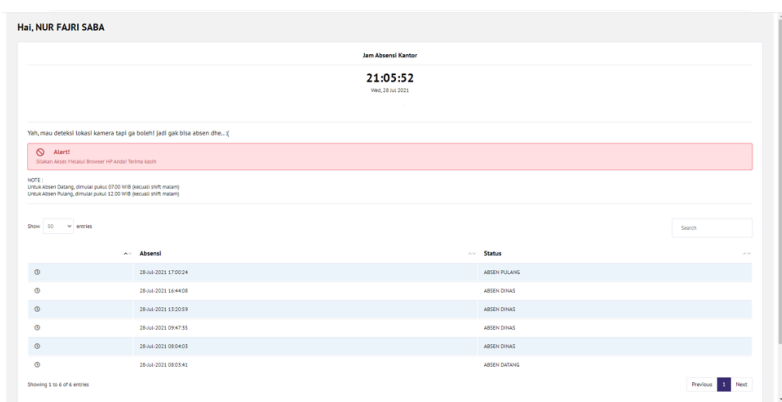

Gambar 10. Layout Halaman Utama

Setelah itu user akan melakukan absensi, maka gambar 11 menampilkan layout halaman absensi. Dan gambar 12, menunjukan laporan absensi yang dilakukan user. 


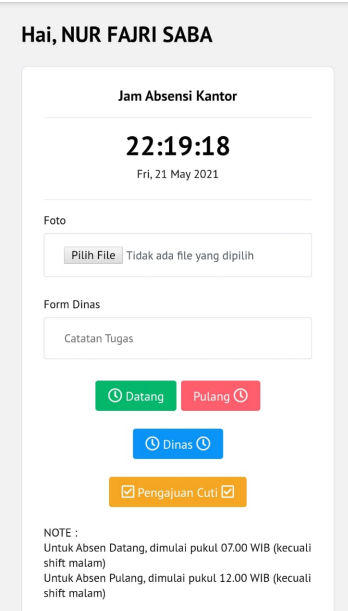

Gambar 12. Layout Halaman Absensi

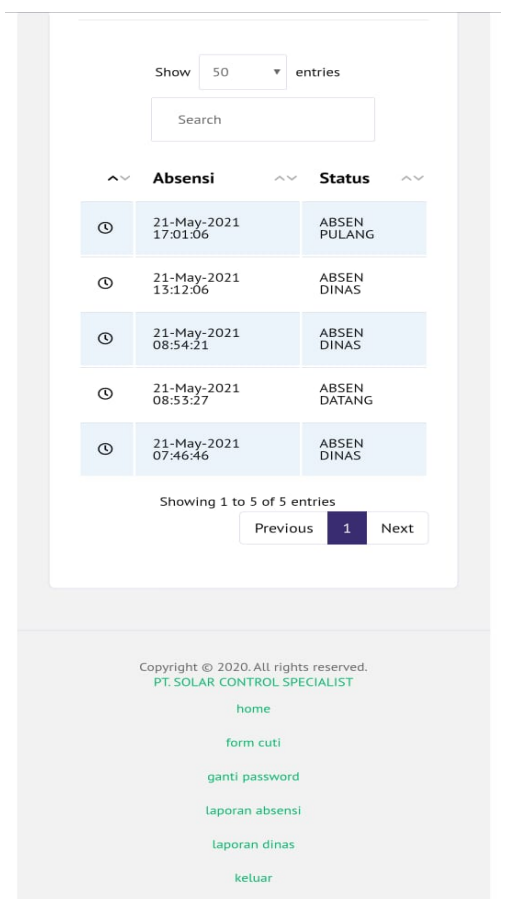

Gambar 13. Layout Halaman Laporan Absensi

Gambar 14 menunjukkan layout tampilan untuk halaman pengajuan cuti, dan laporan dari data kehadiran dapat di unduh ke dalam format excel seperti yang digambarkan dalam gambar 15.

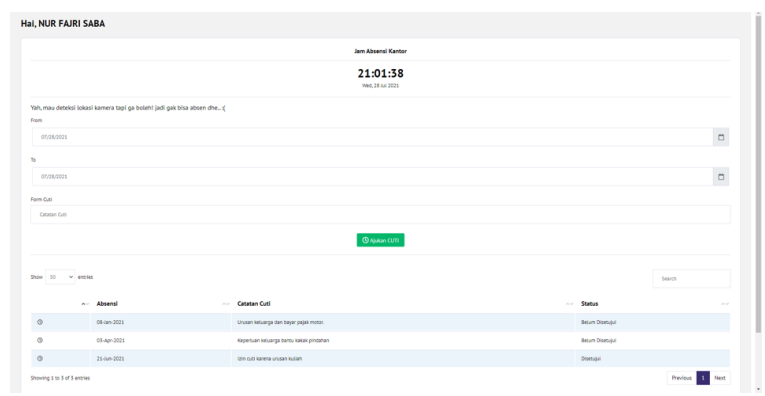

Gambar 14. Layout halaman pengajuan cuti

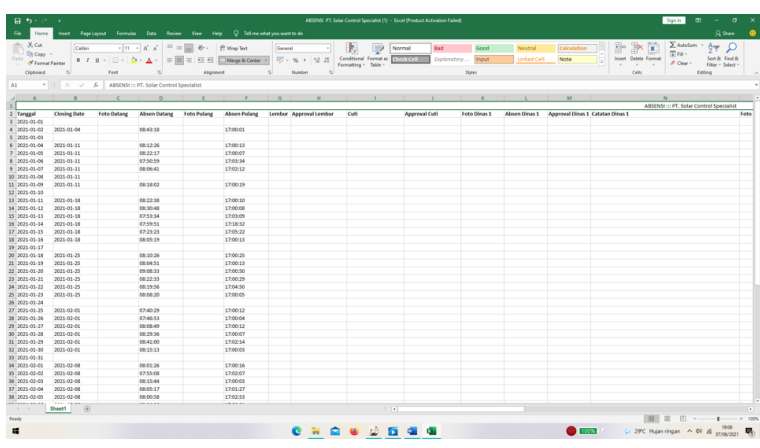

Gambar 15. Layout laporan kehadiran

\section{KESIMPULAN}

Penelitian ini dilakukan untuk meracangan sistem pelaporan absensi berbasis $W e b$ yang akan digunakan pada PT. Solar Controk Specialis. Adapun dalam percangannya, pengembangan sistem ini menggunakan metode Waterfall dimana pada penelitian nin difokuskan pada tahap Requirement Definition serta System and Software Design. Dalam pendefinisian kebutuhan penulis menggunakan metode SWOT Analysis untuk menetukan kebutuhan yang sesuai. Adapun pengumpulan data dilakukan dengan melakukan pengamatan langsung serta melakukan wawancara kepada narasumber guna mengidentifikasi permasalahan yang dihdapai perusahaan. Perancangan sistem dibuat dengan menggunakan UML Diagram disertai dengan perancangan layout sistem. Peneltian ini hanya dilakukan sampai dengan perancangan layout sistem, untuk penelitian selanjutnya dapat dilakukan pengembangan sistem tahap selanjutnya dari metode Waterfall, antara lain; Implementation and Testing, Integration and System Testing, dan Operation and Maintenance. 


\section{DAFTAR PUSTAKA}

[1] Jogiyanto. "Analisis dan Desain Sistem Informasi" Yogyakarta : Andi. 2009.

[2] Mulyanto, Agus. "Sistem Informasi Konsep dan Aplikasi”. Yogyakarta. Pustaka Pelajar. 2009.

[3] Putra, I Wayan Aditya Anggara dan I Gusti Agung Gede Arya Kadyanan. "Pengembangan Front-End Siste, Informasi Mahajemen Absensi Pegawai Avatar
Solutions". Jurnal Elektronil Ilmu Komputer Udayana Vol 7 No.3 Februari 2019, hal. 187-194.

[4] Roosdianto, Rully, Ani Oktarini Sari dan Arief Satriansyah. " Rancang Bangun Sistem Informasi Absensi Karyawan Online”. Inti Nusa Mandiri Vol 15 No.2 Februari 2021 hal. 135-142.

[5] Whitten, J.L. \& Bentley, L.D. "System Analysis \& Design Methods: Sixth Edition". New York: Mc.Graw-Hil. 2004. 